\title{
Dose and drug changes in chronic lymphocytic leukemia cell response in vitro: A comparison of standard therapy regimens with two novel cyclin-dependent kinase inhibitors
}

\author{
MAŁGORZATA KUBCZAK ${ }^{1}$, ALEKSANDRA SZUSTKA ${ }^{1}$, JERZY Z. BŁOŃSKI ${ }^{2}$, TOMAŠ GUCKÝ ${ }^{3}$, \\ MAŁGORZATA MISIEWICZ ${ }^{2}$, VLADMIR KRYSTOF ${ }^{4}$, PAWEŁ ROBAK ${ }^{5}$ and MAŁGORZATA ROGALIŃSKA ${ }^{1}$ \\ ${ }^{1}$ Department of Cytobiochemistry, Faculty of Biology and Environmental Protection, University of Lodz, 90-236 Lodz; \\ ${ }^{2}$ Department of Hematology, Medical University of Lodz, 93-510 Lodz, Poland; ${ }^{3}$ Department of Chemical Biology \\ and Genetics, Centre of the Region Haná for Biotechnological and Agricultural Research, Faculty of Science, \\ Palacký University; ${ }^{4}$ Laboratory of Growth Regulators, Faculty of Science, Palacký University \\ and Institute of Experimental Botany AS CR, 78371 Olomouc, Czech Republic; ${ }^{5}$ Department of \\ Experimental Hematology, Medical University of Lodz, 93-510 Lodz, Poland
}

Received April 6, 2018; Accepted February 2, 2019

DOI: $10.3892 / \mathrm{mmr} .2019 .10007$

\begin{abstract}
Chronic lymphocytic leukemia (CLL) treatment is improving; however, some patients do not respond to therapy. Due to the high heterogeneity in disease development, there is an urgent need for personalization of therapy. In the present study, the response of leukemic mononuclear cells to anticancer drugs used for CLL treatment (cladribine + mafosfamide; $\mathrm{CM}$ or $\mathrm{CM}$ combined with rituximab; RCM) was compared with the response to new cyclin-dependent kinase (CDK) inhibitors: BP14 and BP30. Viable apoptotic and necrotic cells were quantified by flow cytometry using propidium iodide and Yo-Pro stains. CDK inhibitors were studied in several doses to determine the reduction of necrosis and simultaneous increase of apoptosis in leukemic cell incubations with anticancer agents. The distinct cell response to applied doses/anticancer agents was observed. Results obtained in the current manuscript confirmed that modulation of doses is important. This was particularly indicated in results obtained at $24 \mathrm{~h}$ of cells incubation with anticancer agent. While an important time for analysis of anticancer response efficacy (monitoring of apoptosis induction potential) seems to be $48 \mathrm{~h}$ of cells exposition to anticancer agents. High variability in response to the drugs revealed that both the nature and the dose of the anticancer agents could be important in the final effect of the therapy. The present findings support the
\end{abstract}

Correspondence to: Dr. Malgorzata Rogalinska, Department of Cytobiochemistry, Faculty of Biology and Environmental Protection, University of Lodz, ul. Pomorska 141/143, 90-236 Lodz, Poland E-mail: malgorzata.rogalinska@biol.uni.lodz.pl

Key words: chronic lymphocytic leukemia, in vitro cell incubations, anticancer agents, apoptosis, necrosis, viability, cyclin-dependent kinase inhibitor, alkylator, monoclonal antibody thesis that personalized medicine, before drug administration in the clinic, could be important to avoid the application of ineffective therapy.

\section{Introduction}

Although the growing range of treatment options for chronic lymphocytic leukemia and for other lymphoproliferative neoplasms has improved patient survival (1-4), these diseases remain incurable. In addition, there are patients who do not respond to the applied therapy. The serious problems associated with the diagnostic procedure and the design of suitable treatments seem to be linked to the coexistence in patient peripheral blood of quiescent and cycling cells population; this constitutes a special challenge in predicting an effective approach for treating CLL patients $(5,6)$.

Differences in cell signaling trafficking, as well as in the expression of factors involved in apoptosis or microenvironmental factors, might contribute to differences (between patients) in the cell response to anticancer agents between patients. In addition, it is well accepted that diversity in the accumulation of genetic aberrations and epigenetic modifications could also account for heterogeneity in the clinical course of CLL (7-9) and the response to therapy $(10,11)$. Moreover, another factor that could imply in the course of CLL as well as response to therapy is the expression of miR-155. This microRNA is associated with the progression of CLL and weak response to therapy (12). The presence of several factors important for disease development reveals the necessity for the use of personalized medicine, by testing the potential reaction of the patient's cells to anticancer drugs before treatment, to avoid administration of an ineffective regimen (8,13-16). Therefore, it is very important to search for new anticancer agents with the potential to induce apoptosis in CLL cells (17-20).

Cyclin-dependent kinases (CDK) are fundamental factors involved in the regulation of the cell-cycle, transcription 
and apoptosis. Their frequent deregulation in cancers provides novel targets for pharmacological intervention in oncology (21). Various small-molecule CDK inhibitors have been developed, including CDK4/CDK6-specific palbociclib and ribociclib, recently FDA-approved for multiple myeloma and breast cancer, respectively $(22,23)$. Besides the cell cycle, CDKs play critical roles also in a non-proliferative CLL and in cell lines where the CDK inhibitor flavopiridol has been designed as an orphan drug for CLL (24). Flavopiridol however suffers several side effects, such as significant toxicity including high rates of major tumor lysis syndrome, cytokine release syndrome and secretory diarrhea (24). Other CDK inhibitors are therefore studied as new drugs for CLL, such as roscovitine, dinaciclib or SNS-032 (25). These compounds target multiple CDKs, including CDK1, CDK2, CDK5, CDK7 and CDK9, and trigger cytotoxic effects through interruption of the transcription of key antiapoptotic genes responsible for sustenance of the leukemia cell, such as MCL-1 $(21,24)$.

We have recently modified roscovitine to increase its potency and the optimization yielded new 2-substituted-6-biarylmethylamino-9-cyclopentylpurine derivatives BP14 and BP30, which display selective and potent inhibition of CDKs 1, 2, 7 and 9 with low nanomolar $\mathrm{IC}_{50}$ values (26). Both BP14 and BP30 exhibit strong cytotoxicity in human cancer cell lines that correlate with robust CDK1 and CDK2 inhibition and caspase activation. BP14 has demonstrated efficacy against xenografted human liver carcinomas, effectively repressing tumor growth (27). In addition, BP14 potently inhibited transcriptional regulator CDK9 and downregulated anti-apoptotic protein MCL-1 $(27,28)$, key mediator of CLL-cell survival.

The aim of the current work was to observe the importance of drug doses for anticancer response in leukemic cells. For this purpose we have compared the apoptosis induction potential of new CDK inhibitors as potential drugs for CLL and compare them with standard treatments. The present study compares the cytotoxicity (cell viability, apoptosis or necrosis level) of novel roscovitine derivatives BP14 and BP30 and anticancer drugs used in hematological clinics for treating CLL (CM, cladribine + mafosfamide; RCM, rituximab + cladribine + mafosfamide) on controls and leukemic cells obtained from peripheral blood of CLL patients untreated with anticancer agents.

\section{Materials and methods}

Drugs and treatments. The studied compounds BP14 ( $N^{2}$-(trans-4 -aminocyclohexyl)-9-cyclopentyl- $N^{6}$-[[6-(2-furanyl)-3-piridinyl] methyl]-9H-purine-2,6-diamine) and BP30 ( $N^{2}$-(trans-4-aminocyclohexyl)-9-cyclopentyl- $N^{6}$-[[6-(2-thienyl)-3-pyridinyl]methyl] $-9 H$-purine-2,6-diamine) were synthesized and characterized as described in our previous report (26). The identities of the compounds were confirmed by mass spectrometry, NMR and elemental analysis. The purity of the compounds was at least 99.5\%. $10 \mathrm{mM}$ stock solutions of the compounds were prepared in DMSO. The final DMSO concentrations did not exceed $0.1 \%$, a concentration verified not to affect respective experimental parameters.

Cladribine (Biodrybin) and rituximab were obtained from the Institute of Biotechnology and Antibiotics (Warsaw, Poland) and from Roche (Basel, Switzerland), respectively.
Table I. Characteristics of patients.

\begin{tabular}{lcccc}
\hline $\begin{array}{l}\text { Patient } \\
\text { number }\end{array}$ & Sex & $\begin{array}{c}\text { Age, } \\
\text { years }\end{array}$ & $\begin{array}{c}\text { Leukocytosis } \\
\left(\times 10^{3} / \mu 1\right)\end{array}$ & $\begin{array}{c}\text { Rai } \\
\text { stage }\end{array}$ \\
\hline 12 & M & 81 & 470 & 4 \\
14 & M & 57 & 700 & 3 \\
15 & M & 65 & 60 & 4 \\
16 & F & 66 & 153 & 4 \\
17 & M & 54 & 262.3 & 2 \\
\hline
\end{tabular}

M, male; F, female.

Mafosfamide was purchased from Niomech IIT GmbH (Bielefeld, Germany). These three drugs were used in the following combinations: $\mathrm{CM}$ (cladribine + mafosfamide), RCM (rituximab + cladribine + mafosfamide). The concentration of the drugs used for cell incubations were as follows: Cladribine $50 \mathrm{ng} / \mathrm{ml}(139 \mathrm{nM})$, mafosfamide $1 \mu \mathrm{g} / \mathrm{ml}(2.4 \mu \mathrm{M})$, rituximab $20 \mu \mathrm{g} / \mathrm{ml}(170 \mathrm{nM})$. Cells incubated only with medium or with appropriately diluted DMSO served as a control.

Patients. Blood samples were obtained from five CLL patients: One female patient and four male (cooperation with the Department of Hematology, Medical University of Lodz, Poland; Head: Prof. T. Robak). The median age was 65 years (54-81). Leukocytosis ranged from 60 to $700 \times 10^{3} / \mu 1$ (Table I). Samples were collected on EDTA to sterile, disposable tubes. Cell marker studies were performed to confirm B-cell origin and monoclonal proliferation. All B lymphocytes were CD5, CD19 and CD23 positive.

Ethics statement. The study was approved by the Local Ethics Committee from the University of Lodz (20/KBBM-UŁ/2015 and 5/KBBMUŁ/2017).

Isolation of mononuclear cells and cell cultures with anticancer agents. Mononuclear cells were isolated from CLL samples by centrifugation on a Histopaque 1077 gradient (900 rpm, $19 \mathrm{~min}, 24^{\circ} \mathrm{C}$ ). The obtained cells were resuspended in RPMI-1640 medium with $10 \%$ fetal bovine serum, $2 \mathrm{mM}$ L-glutamine, $100 \mathrm{U} / \mathrm{ml}$ penicillin and $100 \mu \mathrm{g} / \mathrm{ml}$ streptomycin. The cell culture density was $3 \times 10^{6} / \mathrm{ml}$. In the next step, the cells were incubated with drugs/novel anticancer compounds. After 24 and $48 \mathrm{~h}$ of cell incubations with anticancer agents cell viability was tested.

Flow cytometry analysis. Cell viability, the rate of apoptosis and necrosis were estimated using a Vybrant Apoptosis Assay \#4 kit after 0,24 and $48 \mathrm{~h}$, as in previous studies $(14,15)$. The early apoptotic cells were marked with YO-PRO fluorescent dye, and late apoptotic and necrotic cells with propidium iodide. For flow cytometry analysis, $1 \times 10^{6} / \mathrm{ml}$ cells were used, centrifuged $\left(5,000 \mathrm{rpm}, 5 \mathrm{~min}, 24^{\circ} \mathrm{C}\right)$, then resuspended in phosphate buffer saline (PBS) containing fluorescent dyes. Samples were incubated in the dark for $20 \mathrm{~min}$ and then analyzed. 

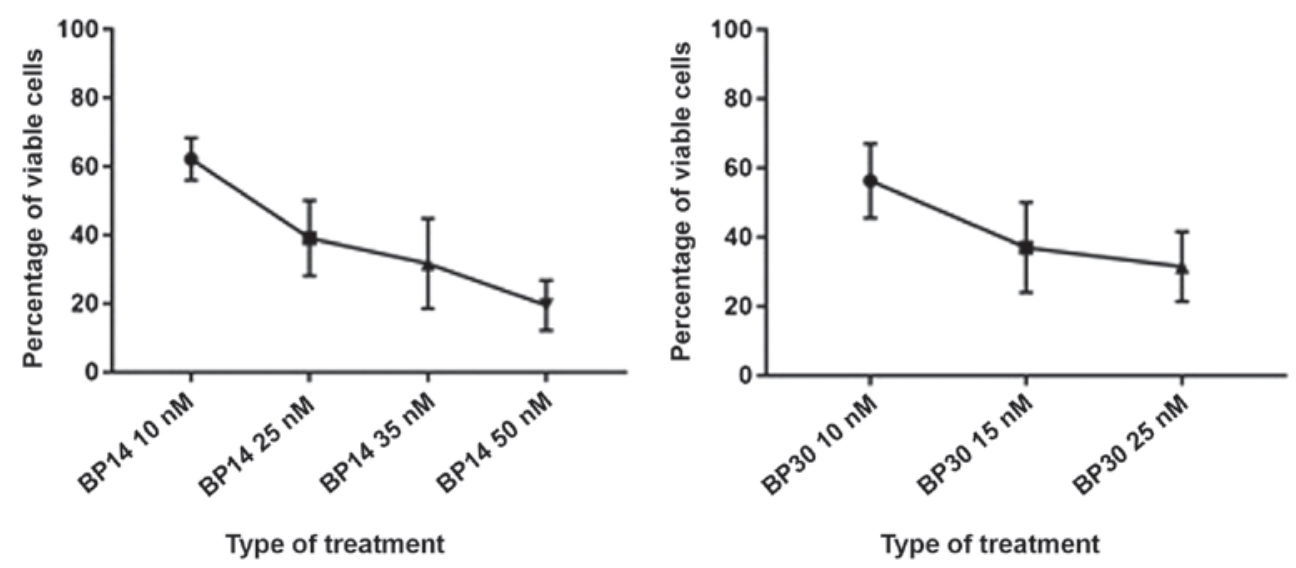

Figure 1. Dose-response effect of BP14 and BP30 on the viability of CLL cells following 48-h incubations. Data are presented as the mean \pm standard error of the mean $(n=6)$.

A a

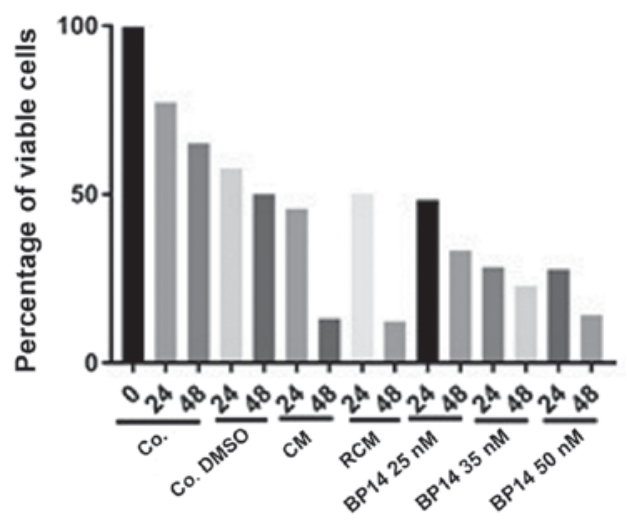

b

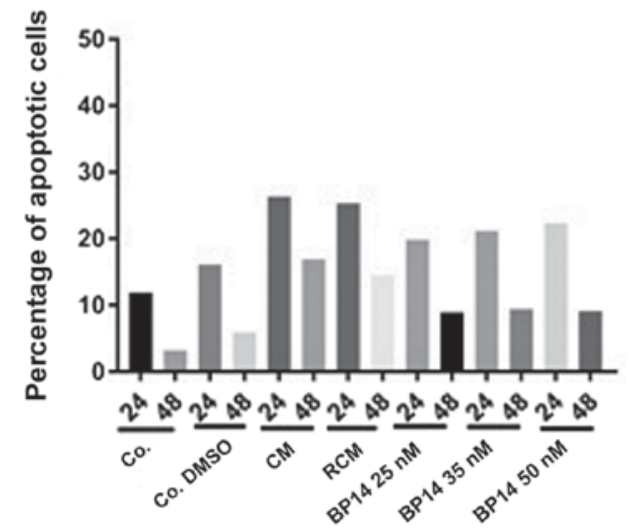

C

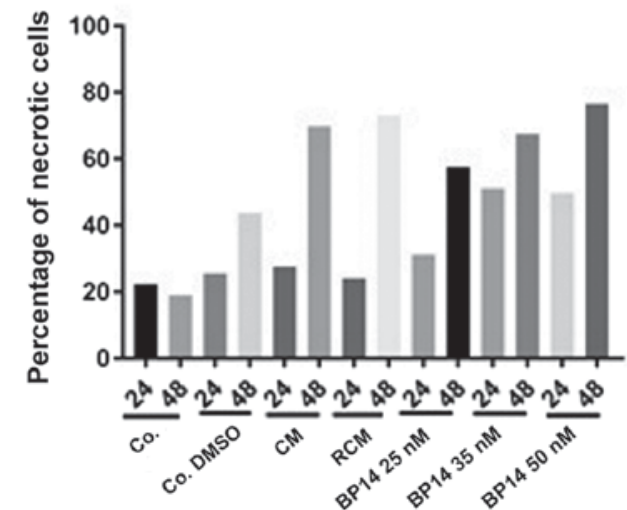

B
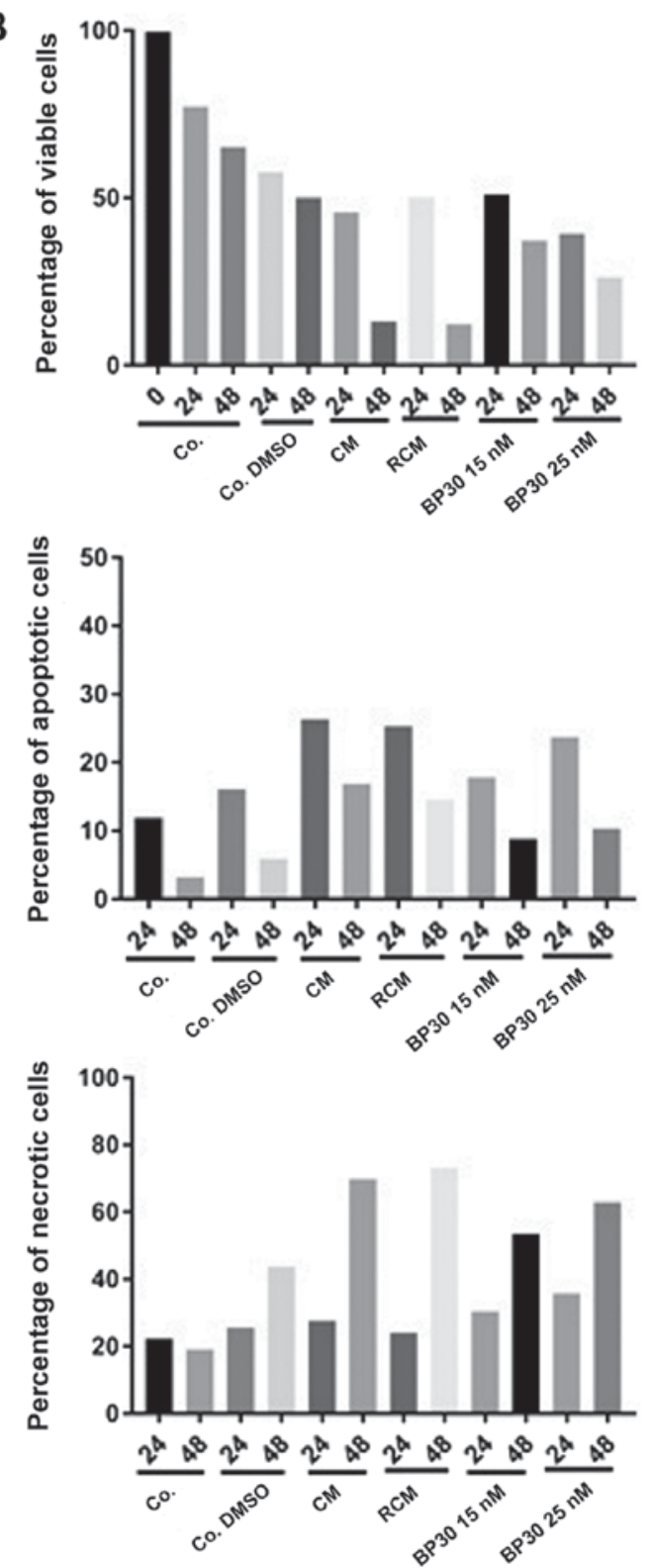

Figure 2. (A) Determination of (a) cell viability, (b) level of apoptosis or (c) necrosis. CLL cells (Patient no. 15) were incubated for $48 \mathrm{~h}$ without drugs (Co. or Co. DMSO) or with CM, RCM or CDK inhibitors (A) BP14 and (B) BP 30. Co., untreated control; Co. DMSO, control with dimethyl sulfoxide; $\mathrm{CM}$, cladribine combined with mafosfamide; RCM, CM combined with rituximab; CDK, cyclin-dependent kinase. 


\section{Patient 15}
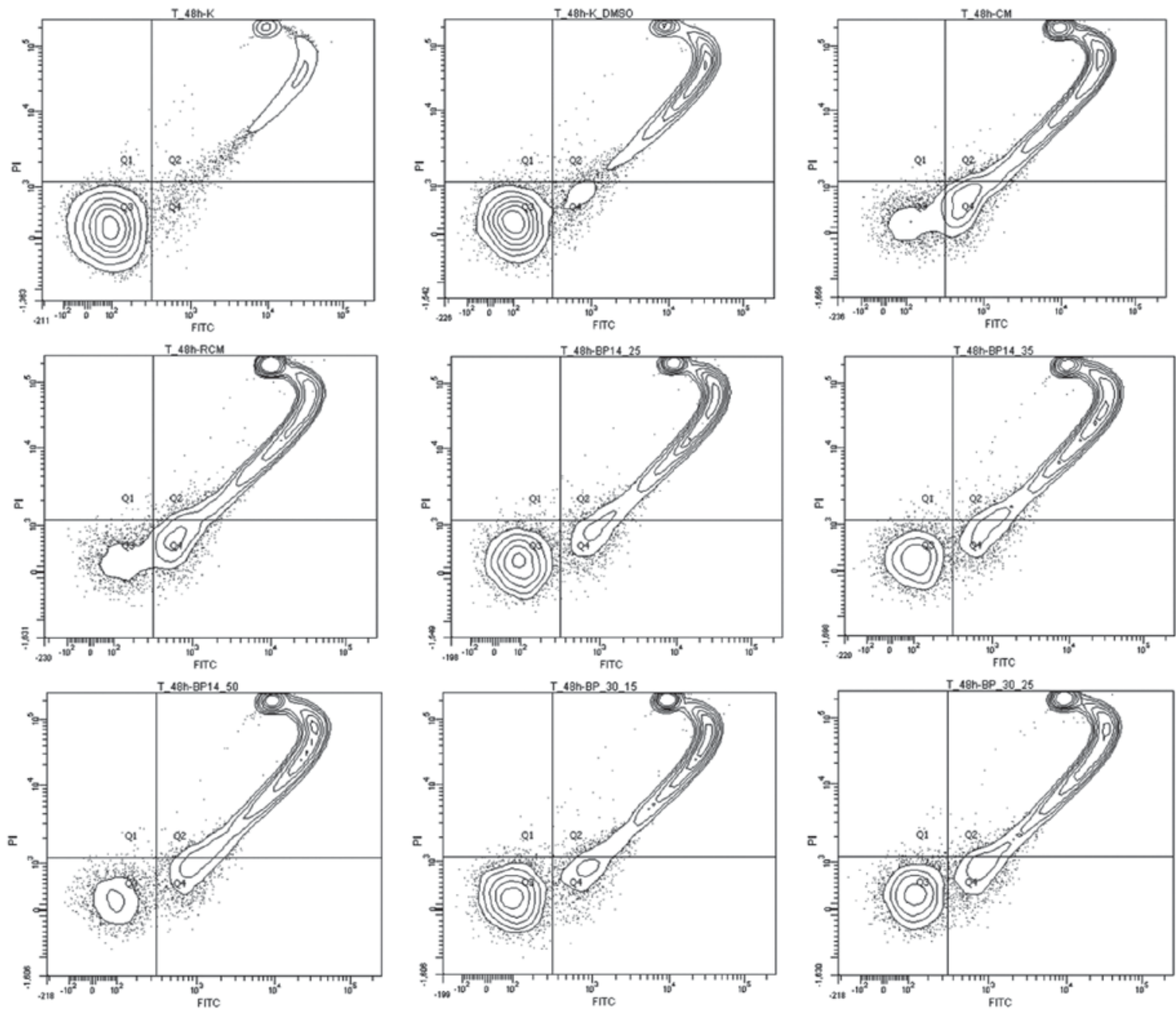

Figure 3. Graph plots of cell viability (Q3), apoptotic (Q4), necrotic and late apoptotic cells (Q2), debris (Q1). CLL cells (Patient no. 15) were incubated for $48 \mathrm{~h}$ without drugs (Co. or Co. DMSO) or with anticancer drugs (CM or RCM) or CDK inhibitors in several doses BP14.25, BP14.35, BP14.50, and BP 30.15, BP 30.15. BP 30.25. Co., untreated control; Co. DMSO, control with dimethyl sulfoxide; CM, cladribine combined with mafosfamide; RCM, CM combined with rituximab; CDK, cyclin-dependent kinase.

Statistical analysis. Statistical analysis were performed by Kruskal Wallis test with Dunn's multiple comparison test. The statistical differences between the control sample (Co.) and samples with the addition of the anticancer agent was analyzed, respectively. Statistical analysis were obtained for $\mathrm{N}=5 ;{ }^{*} \mathrm{P}<0.05,{ }^{* *} \mathrm{P}<0.001,{ }^{* * *} \mathrm{P}<0.0001$.

\section{Results}

Peripheral mononuclear cells from the group of 6 patients with CLL were exposed to varying concentrations of novel CDK inhibitors (BP14 and BP30). The representative results for patients ( 3 presented as single cases and 2 combined figures with statistics) were included in current manuscript, showing distinct patients response to anticancer agents. The effect of CDK inhibitors on CLL cells were analysed for 6 CLL patients and compared with standard chemotherapeutic regimens (CM, cladribine + mafosfamide; RCM, rituximab + cladribine + mafosfamide), as described in our previous studies with more than 50 patients $(14,15)$. The CLL cells isolated from peripheral blood of patients were incubated with anticancer agents for 24 and $48 \mathrm{~h}$, harvested and then analyzed for viability, apoptosis and necrosis by flow cytometry. Both studied CDK inhibitors decreased the viability of the CLL cells in a dose-dependent manner (Fig. 1). At the concentration of $25 \mathrm{nM}$, the median reduction $\left(\mathrm{IC}_{50}\right)$ for all patients in cell viability for both $\mathrm{CDK}$ inhibitors was similar, 39.1 and $31.5 \%$ for BP14 and BP30, respectively (Fig. 1).

Next we have analysed CLL viability and the level of necrosis upon treatment with anticancer agents. The cells of patient no. 15 showed increasing level of necrosis after $24 \mathrm{~h}$ exposition to all used anticancer agents but with distinct extend. The cells obtained from patient no. 15 were very sensitive toward all anticancer agents (Figs. 2 and 3). The strong reduction in cell viability was observed for all used types of treatment, but the most spectacular effect was noticed when cell were incubated for $48 \mathrm{~h}$ with $\mathrm{CM}$ and RCM. Moreover, the increase in apoptosis level ( $24 \mathrm{~h}$ incubation) and the high value of necrosis (48 h) was a consequence of dynamics in apoptosis realization. The high level of necrosis after $48 \mathrm{~h}$ of cell exposition to anticancer agents could be a compilation of necrosis as well as advanced apoptosis. Therefore, for a 

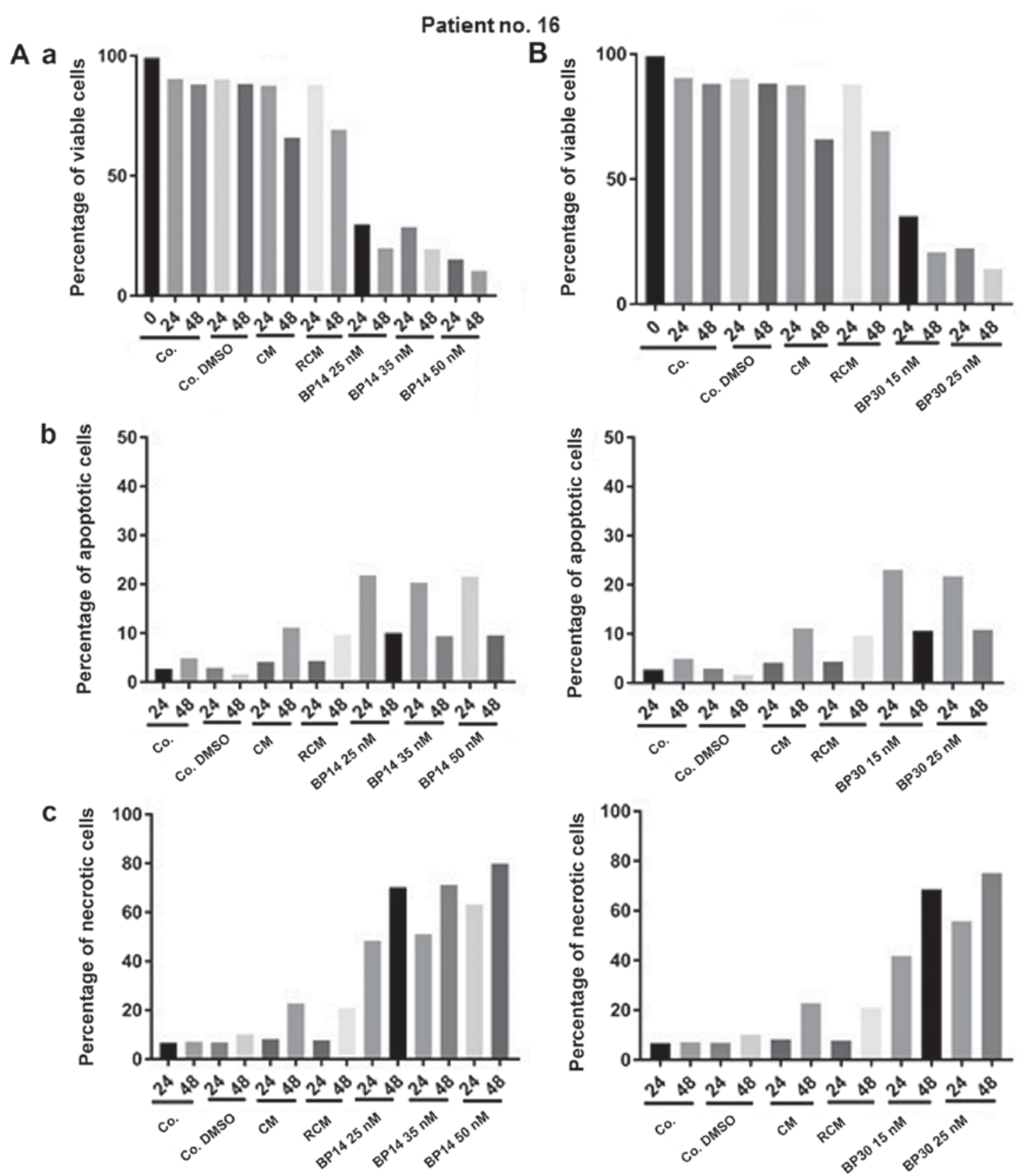

Figure 4. (A) Determination of (a) cell viability, (b) level of apoptosis or (c) necrosis. CLL cells (Patient no. 16) were incubated for $48 \mathrm{~h}$ without drugs (Co. or Co. DMSO) or with CM, RCM or CDK inhibitors (A) BP14 and (B) BP 30. Co., untreated control; Co. DMSO, control with dimethyl sulfoxide; CM, cladribine combined with mafosfamide; RCM, CM combined with rituximab; CDK, cyclin-dependent kinase.

proper modulation of doses value a special importance should be given to results obtained at $24 \mathrm{~h}$ of cells incubation with anticancer agents. While for monitoring of apoptosis induction potential an important time for analysis of anticancer response efficacy seems to be $48 \mathrm{~h}$ of cells exposition to anticancer agents (Fig. 2).

The results obtained for representative patient no. 16 show the potential resistance of patient's cells to drug combinations used in hematological clinics for CLL treatment. For this point only BP14/BP30 reflect to be active in apoptosis induction. Moreover, BP30 and BP14 in all used doses induced very fast apoptosis. The cells of patient no. 16 (Figs. 4 and 5) demonstrated resistance to $\mathrm{CM}$ and $\mathrm{RCM}$, as well as sensitivity to each analyzed dose of CDK inhibitors (BP14 and BP30). Interestingly, the level of apoptosis in patients no. 16's cells for each dose of BP14 and BP30 was relatively constant, but increasing levels of necrosis/late apoptosis were observed.

The comparative analysis of patient no. 17 reflects the opposite reaction to patient no. 16. The cells of patient no. 17 (Fig. 6) were sensitive to both standard CLL treatments (CM and RCM), but displayed resistance to CDK inhibitors, which was clear in all assays, including cell viability, apoptosis and necrosis.

Finally, the comparative analysis of the results of the $24 \mathrm{~h}$ (A) and $48 \mathrm{~h}$ (B) CLL cell incubations with anticancer agents for five patients (Table I) are presented on Fig. 7 (for BP14) and Fig. 8 (for BP30), with a statistical analysis performed by the Kruskal-Wallis test. It must be stated that these combined results are difficult to compare with those of each single patient. It is important to note that the results for patients 15 , 

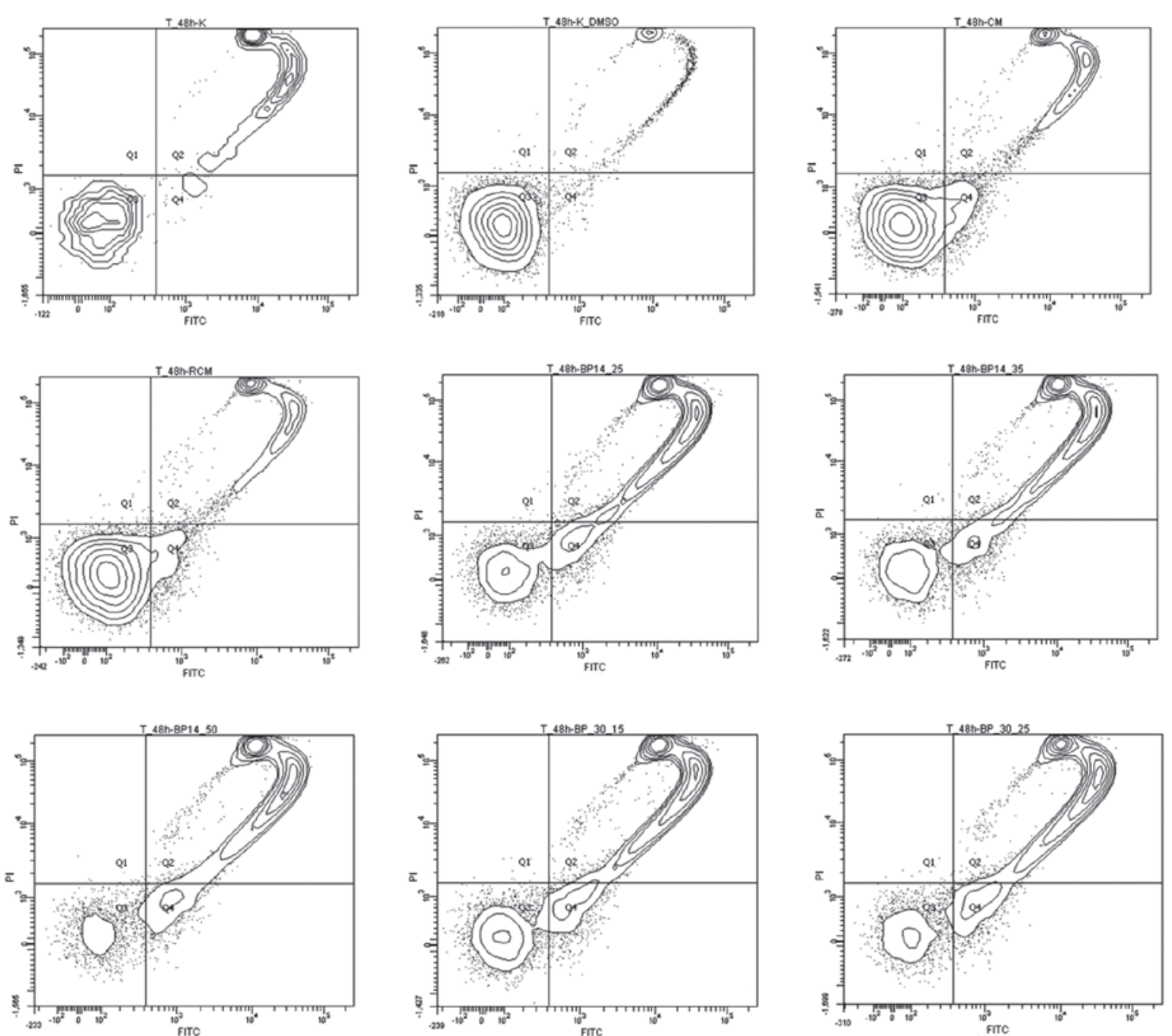

Figure 5. Graph plots of cell viability (Q3), apoptotic (Q4), necrotic and late apoptotic cells (Q2), debris (Q1). CLL cells (Patient no. 16) were incubated for 48 h (Co. or Co. DMSO) or with anticancer drugs (CM or RCM) or CDK inhibitors in several doses BP14.25, BP14.35, BP14.50, and BP 30.15, BP 30.15. BP 30.25. Co., untreated control; Co. DMSO, control with dimethyl sulfoxide; CM, cladribine combined with mafosfamide; RCM, CM combined with rituximab; CDK, cyclin-dependent kinase.

16 or 17 presented here indicate that the median results presented in scientific papers usually provide incorrect recommendations (13-15) concerning patient resistance/sensitivity to anticancer agents, and these would not be effective in treating patient no. 16.

\section{Discussion}

During CLL development, long-lived B lymphocytes accumulate in peripheral blood and in other lymphatic organs of patients with the advanced form of the disease (29). This accumulation occurs due to suppression of apoptosis and usually happens in the resting form of the disease $(9,29)$. Since the disease could transform into an active form, the coexistence of quiescent and cycling cell populations complicate the diagnostics and prediction of therapy efficacy $(5,6)$. Therefore, an analysis of the chemosensitivity profile of patient cells prior to therapy followed by the use of personalized medicine based on apoptosis induction would markedly reduce the ineffective treatment $(8,13-15)$.
The current study compares cytometric analyses of cell viability, the levels of apoptosis and necrosis in ex vivo CLL cells isolated from five patients to determine whether the response has some connection with the type of used anticancer agents. The special attention was given for observation of the role of anticancer agent doses on cell response.

Our findings reveal significant differences in the response to anticancer agents among leukemic patients, as noticed in previous studies $(8,14,15)$. Moreover, our results show that the comparison of cell viability, apoptosis rate, and the level of necrosis underline the importance of proper anticancer agent dose selection to avoid the occurrence of a high necrosis level that could transform in vivo into inflammation. To eliminate potential resistance to therapy, the therapeutic approach should be chosen before drug administration in the clinic using personalized therapy tests $(14,15)$. Such techniques have good value for predicting CLL cell sensitivity to anticancer drugs. This prediction is of importance as it allows for the optimal course of therapy to be chosen for the patient, thus avoiding ineffective anticancer administration and minimizing the level 
Patient no. 17
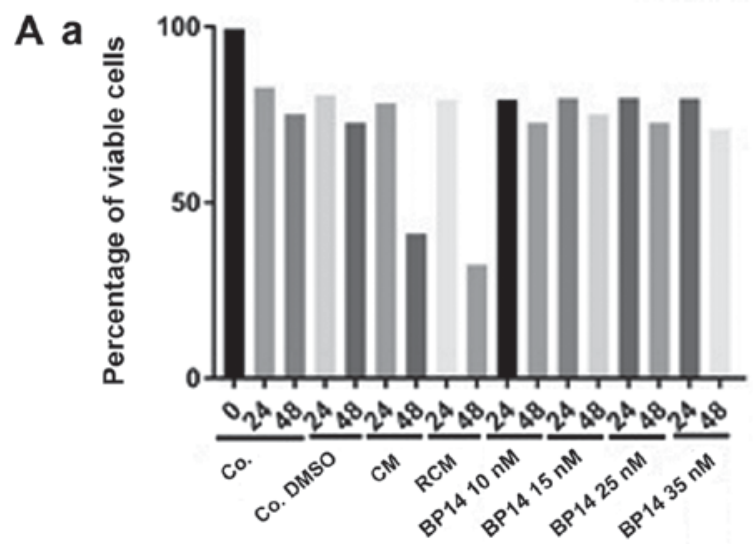

b

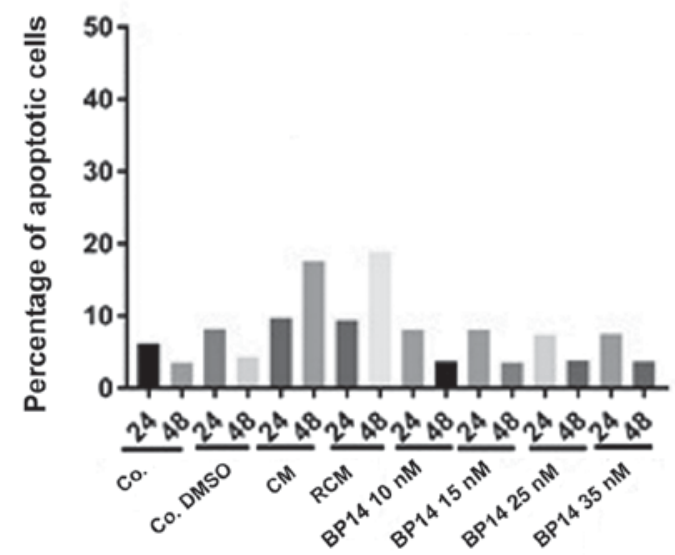

C

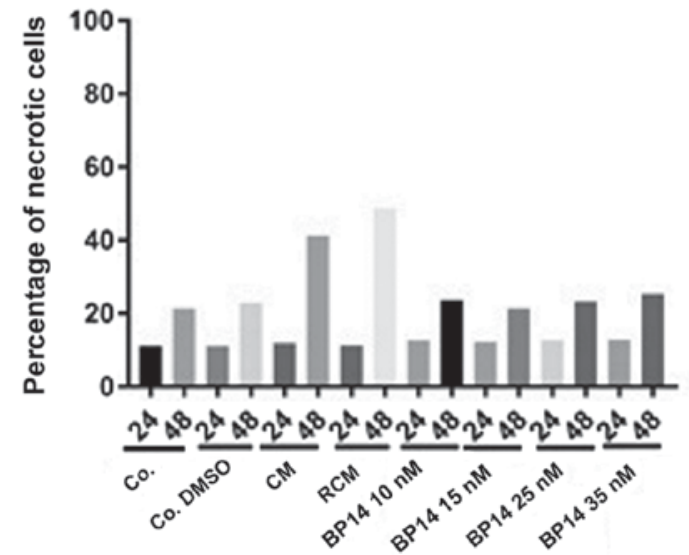

B
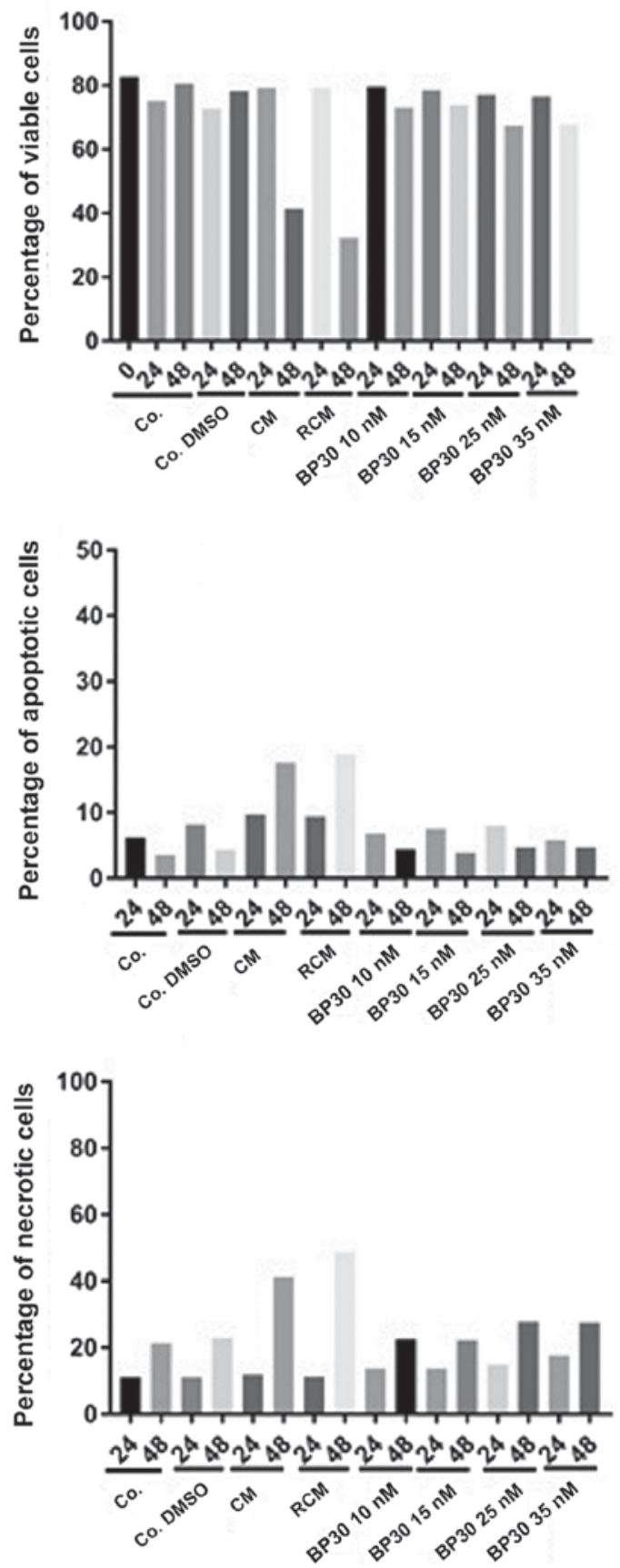

Figure 6. (A) Determination of (a) cell viability, (b) level of apoptosis or (c) necrosis. CLL cells (Patient no. 17) were incubated for $48 \mathrm{~h}$ without drugs (Co. or Co. DMSO) or with CM, RCM or CDK inhibitors (A) BP14 and (B) BP 30. Co., untreated control; Co. DMSO, control with dimethyl sulfoxide; CM, cladribine combined with mafosfamide; RCM, CM combined with rituximab; CDK, cyclin-dependent kinase.

of necrosis that could influence the activity of the drug in vivo. In order to expand the range of possible therapeutic options for leukemia treatment, there is an urgent need to identify new compounds with anticancer properties.

Recent developments in the field of drug discovery include the identification of potent CDK inhibitors. Currently, it is not clear whether highly CDK specific inhibitors, such as palbociclib, or pan-CDK specific inhibitors, such as flavopiridol or dinaciclib, are more suitable for cancer therapy. A number of studies have found them to have promising efficacy when used in combination with standard anticancer drugs or with other molecularly targeted agents (21). The procedure for identifying cancers that can respond to a particular course of therapy has also been frequently discussed. CDK inhibitors have also been widely studied in CLL in clinical settings. For example flavopiridol, SNS032 or dinaciclib have demonstrated activity against CLL, but have also caused a significant decrease in cell viability (24,30-33). These CDK inhibitors downregulate mRNA and protein expression of the important anti-apoptotic proteins of the $\mathrm{BCL}_{2}$ family such as MCL1 and BCL-xL and block oncogenic pathways (e.g. STAT3, MAPK, NF-кB), which have been shown to be essential for CLL cell survival $(25,34)$.

The present study examines the anti-CLL potential of two novel CDK inhibitors that have already displayed high 
A

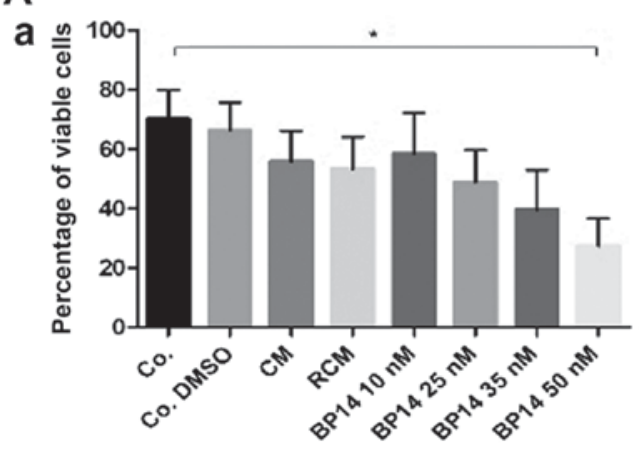

Type of treatment

b

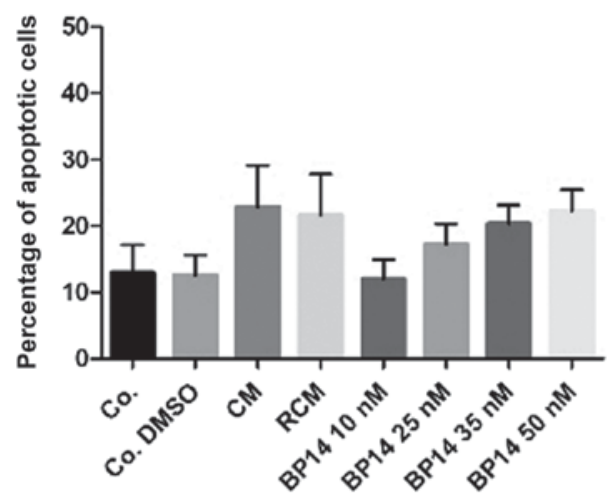

Type of treatment

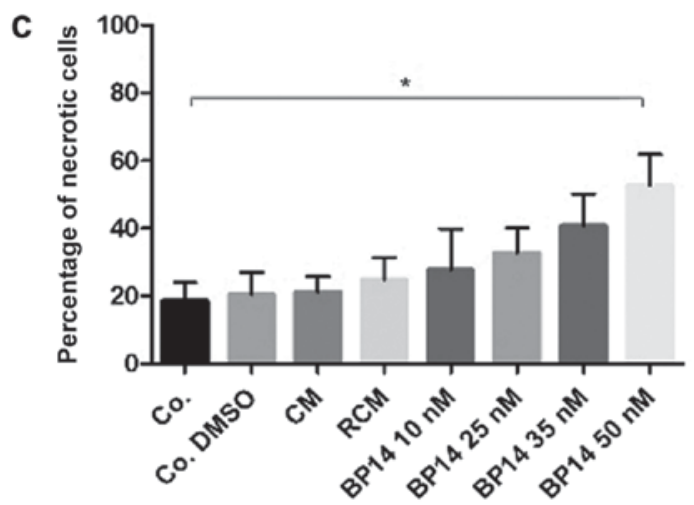

Type of treatment

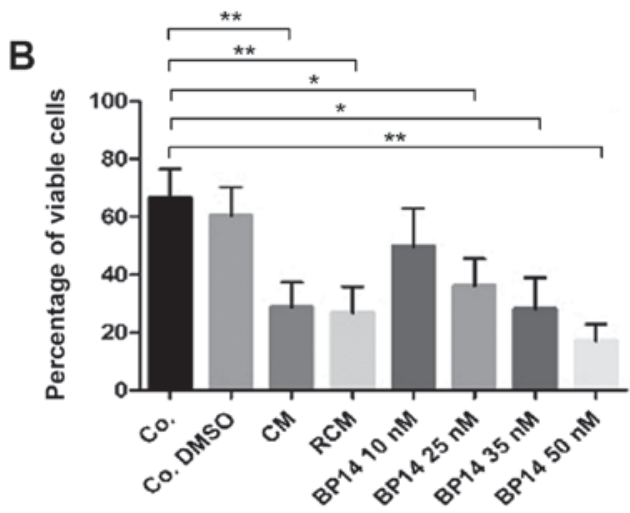

Type of treatment

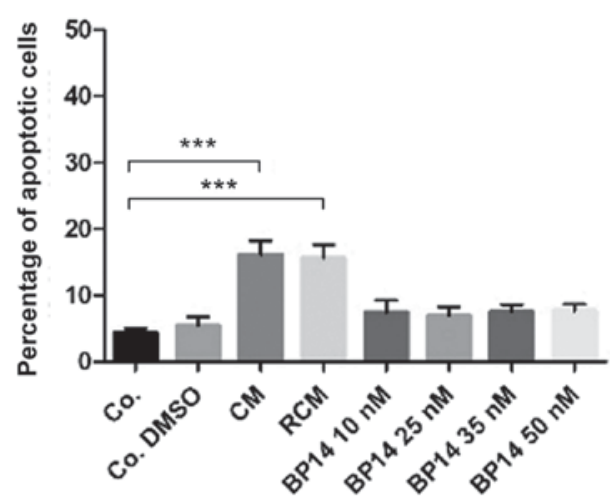

Type of treatment

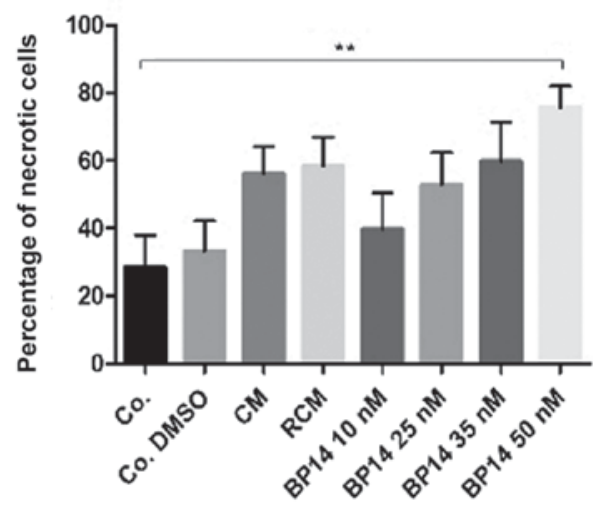

Type of treatment

Figure 7. (A) Determination of (a) cell viability, (b) level of apoptosis or (c) necrosis. CLL cells were incubated for $48 \mathrm{~h}$ without anticancer agents (Co. or Co. DMSO) or with anticancer drugs $(\mathrm{CM}$ or $\mathrm{RCM})$ or purine analog BP14. $\mathrm{N}=5$; data are presented as the mean \pm standard deviation $(\mathrm{n}=5) .{ }^{*} \mathrm{P}<0.05,{ }^{* *} \mathrm{P}<0.001$ and ${ }^{* * *} \mathrm{P}<0.0001$. Statistical analysis were performed using the Kruskal Wallis test. Results were obtained after (A) 24 and (B) $48 \mathrm{~h}$ of leukemic cell exposure to anticancer agents. Co., untreated control; Co. DMSO, control with dimethyl sulfoxide; CM, cladribine combined with mafosfamide; RCM, CM combined with rituximab.

anticancer activity (26). Our results further support previous findings that CDK inhibitors induce apoptosis usually much faster than standard treatments used for CLL patients (24). However, a high variability noticed in disease development (29) translates on individual patient sensitivity to anticancer agents. Our recent findings reveal that the dose of the anticancer drug strongly influences the response to treatment. While the correct dose of the active drug will induce a high level of apoptosis and should lead to natural cell elimination by programmed cell death. The high dose usually induces necrosis, which could induce inflammation. In addition, our findings demonstrate that drug dose could play an important role in the modulation of leukemic cell response to the anticancer agent(s). It has also been found that 5-HT7 receptors play a role in the induction of inflammation by release of sirtuin, a nicotinamide adenine dinucleotide-dependent deacetylase that could influence gene expression (35), as well as in the level of serotonin regulation (36). Therefore, it is possible that an excessive dose of a drug induces a high level of necrosis, and that could be transferred into inflammation. It might also have an impact on the diversities in cell signaling. Interestingly, it has been suggested that inflammation could cause conditions directed 
A

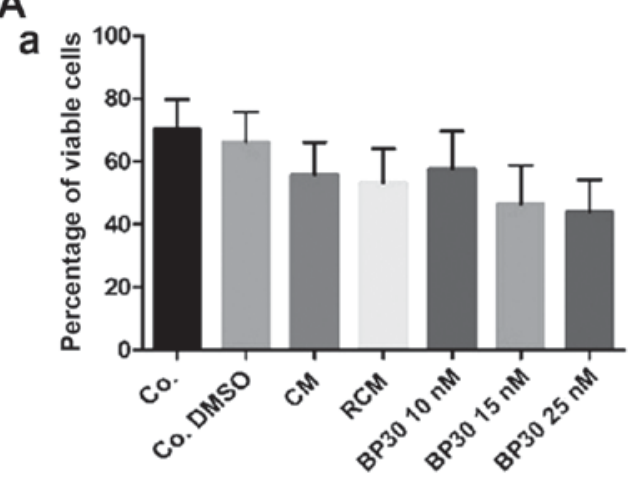

Type of treatment

b

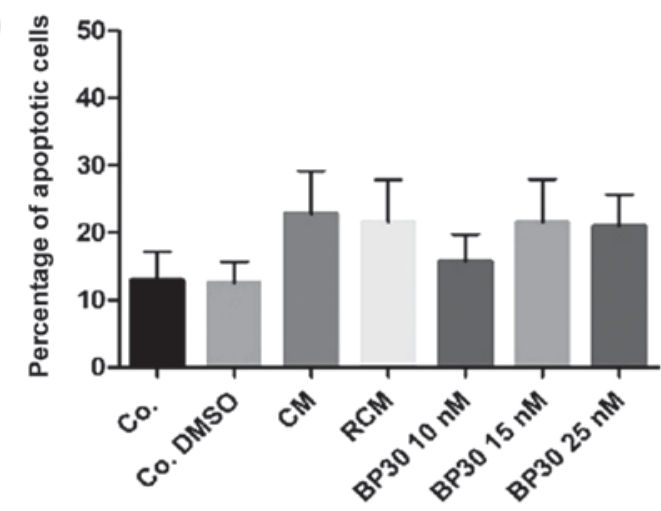

Type of treatment

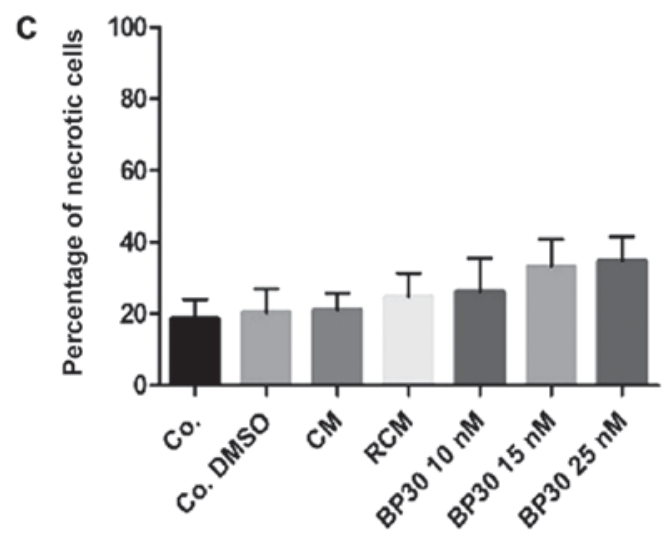

Type of treatment
B
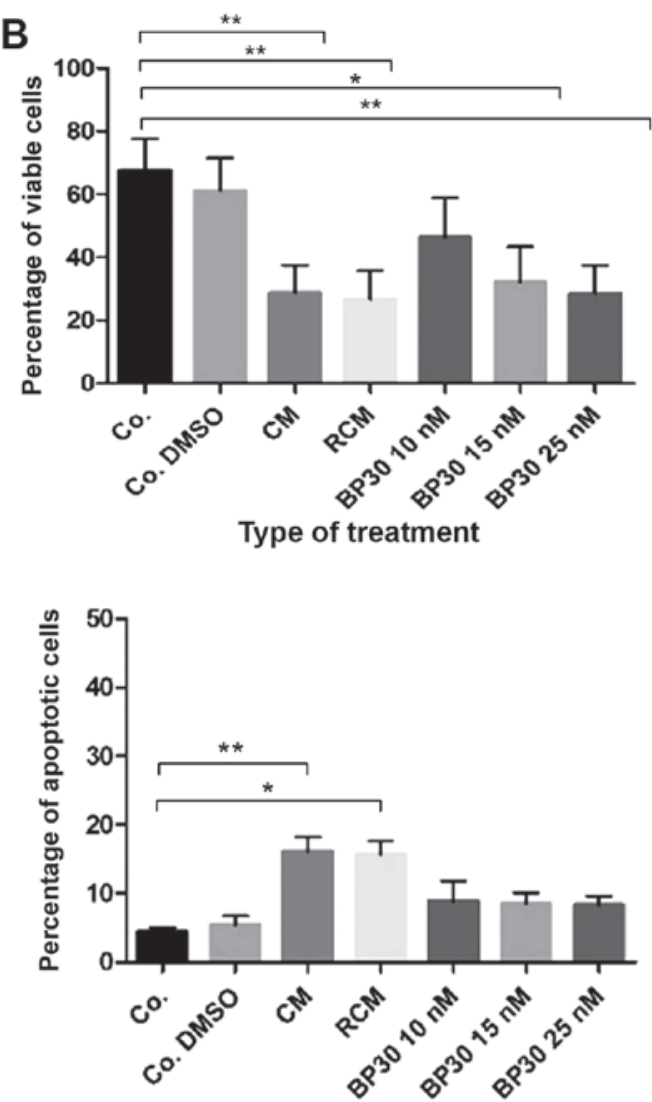

Type of treatment

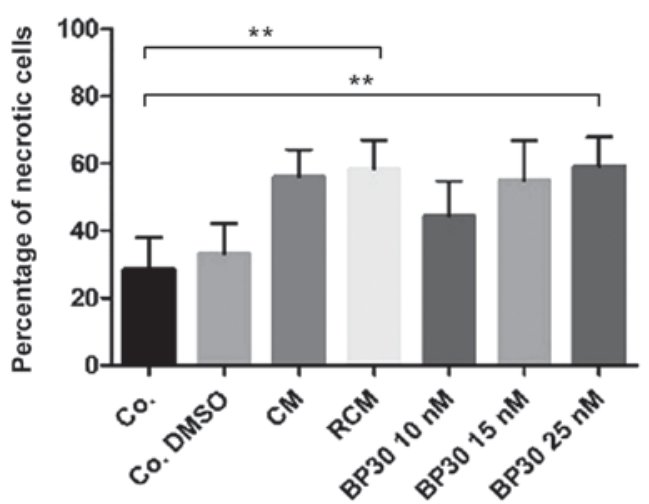

Type of treatment

Figure 8. Determination of (a) cell viability, (b) level of apoptosis or (c) necrosis. CLL cells were incubated for $48 \mathrm{~h}$ without anticancer agents (Co. or Co. DMSO) or with anticancer drugs (CM or RCM) or purine analog BP30. $\mathrm{N}=5$; data are presented as the mean \pm standard deviation $(\mathrm{n}=5)$. ${ }^{*} \mathrm{P}<0.05$ and ${ }^{* * *} \mathrm{P}<0.001$. Statistical analysis were performed using the Kruskal Wallis test. Results were obtained after (A) 24 and (B) $48 \mathrm{~h}$ of leukemic cell exposure to anticancer agents. Co., untreated control; Co. DMSO, control with dimethyl sulfoxide; CM, cladribine combined with mafosfamide; RCM, CM combined with rituximab.

to osteoporosis (37), which can suggest that factors involved in the development of inflammation could also disturb other metabolic pathways, leading to the possible occurrence of a range of other metabolic alterations that could lead to osteoporosis. Interestingly, the aberrant products observed in cancer cells involved in the Krebs cycle could promote cancer progression (38).

The results of our studies confirm the need for personalized therapy for CLL, as such an individual approach would greatly avoid the chance of ineffective treatment being used.
Our findings also highlight the importance of the application of the correct dose for treatment, and demonstrate that the drugs could induce apoptosis at different rates, which can be also monitored in vitro by incubating cells with anticancer agents.

\section{Acknowledgements}

The authors would like to thank Professor Tadeusz Robak (Department of Hematology, Medical University of Lodz, 
Lodz, Poland) for their help with the personalized therapy for CLL, as well as Mr. Edward Lowczowski (Medical University of Lodz) for editorial assistance.

\section{Funding}

The present study was supported by the Ministry of Education, Youth and Sports of the Czech Republic (National Program of Sustainability I; grant no. LO1204), Czech Science Foundation (grant no. 15-15264S) and Palacky University in Olomouc (grant no. IGA_PrF_2018_006). The equipment for cell culture and media was sponsored by the University of Lodz for MSc degrees.

\section{Availability of data and materials}

The datasets used and/or analyzed during the current study are available from the corresponding author on reasonable request.

\section{Authors' contributions}

MK and AS performed the experiments. JZB and PR determined the clinical material characteristics. MM performed and organised the blood transfers in the clinic. TG and VK synthesized the new purine analogs. MR wrote the manuscript, and conceived and designed the experiments. All authors read and approved the final manuscript.

\section{Ethics approval and consent to participate}

The present study was approved by the Local Ethics Committee from the University of Lodz (nos. 20/KBBM-UŁ/2015 and 5/KBBMUŁ/2017). The requirement for written, informed consent was waived.

\section{Patient consent for publication}

Not applicable.

\section{Competing interests}

The authors declare that they have no competing interests.

\section{Refrences}

1. Besbes S, Mirshahi M, Pocard M and Billard C: Strategies targeting apoptosis proteins to improve therapy of chronic lymphocytic leukemia. Blood Rev 29: 345-350, 2015.

2. Cramer P, Eichhorst B, Reinhardt HC and Hallek M: Current strategies to create tailored and risk-adapted therapies for CLL patients. Best Pract Res Clin Haematol 29: 111-121, 2016.

3. Visentin A, Facco M, Frezzato F, Castelli M, Trimarco V, Martini V, Gattazzo C, Severin F, Chiodin G, Martines A, et al Integrated CLL scoring system, a new and simple index to predict time to treatment and overall survival in patients with chronic lymphocytic leukemia. Clin Lymphoma Myeloma Leuk 15: 612-620.e1-5, 2015.

4. Koffman B and Schorr A: The 21st century revolution in CLL: Why this matters to patients. Best Pract Res Clin Haematol 29: 122-132, 2016

5. Klein U and Dalla-Favera R: Germinal centres: Role in B-cell physiology and malignancy. Nat Rev Immunol 8: 22-33, 2008.

6. Hallek M: Chronic lymphocytic leukemia: 2013 update on diagnosis, risk stratification and treatment. Am J Hematol 88: 803-816, 2013
7. Martin-Subero JI, López-Otín C and Campo E: Genetic and epigenetic basis of chronic lymphocytic leukemia. Curr Opin Hematol 20: 362-368, 2013.

8. Rogalińska M, Franiak-Pietryga I, Błoński JZ, Góralski P, Maciejewski H, Janus A, Robak P, Mirowski M, Piekarski H, Robak T and Kiliańska ZM: Toward personalized therapy for chronic lymphocytic leukemia: DSC and cDNA microarray assessment of two cases. Cancer Biol Ther 14: 6-12, 2013.

9. Rodriquez-Vicente AE, Díaz MG and Hernández-Rivas JM: Chronic lymphocytic leukemia: A clinical and molecular heterogenous disease. Cancer Genet 206: 49-62, 2013.

10. Rogalinska M, Goralski P, Wozniak K, Bednarek JD, Blonski JZ, Robak T, Piekarski H, Hanausek M, Walaszek Z and Kilianska ZM: Calorimetric study as a potential test for choosing treatment of B-cell chronic lymphocytic leukemia. Leuk Res 33: 308-314, 2009.

11. Jeyakumar D and O'Brien S: B cell receptor inhibition as a target for CLL therapy. Best Pract Res Clin Haematol 29: 2-14, 2016.

12. Ferrajoli A, Shanafelt TD, Ivan C, Shimizu M, Rabe KG, Nouraee N, Ikuo M, Ghosh AK, Lerner S, Rassenti LZ, et al: Prognostic value of miR-155 in individuals with monoclonal B-cell lymphocytosis and patients with B chronic lymphocytic leukemia. Blood 122: 1891-1899, 2013.

13. Rogalińska M and Kiliańska ZM: Personalised therapy versus targeted therapy, differences in meaning. Glo J Res Anal 4: 5-8, 2015.

14. Rogalińska M, Błoński JZ, Góralski P, Wawrzyniak E, Hartman M, Rogalska A, Robak P, Koceva-Chyła A, Piekarski H, Robak T and Kiliańska ZM: Relationship between in vitro drug sensitivity and clinical response of patients to treatment in chronic lymphocytic leukemia. Int J Oncol 46: 1259-1267, 2015.

15. Rogalińska M, Góralski P, Błoński JZ, Robak P, Barciszewski J, Koceva-Chyła A, Piekarski H, Robak T and Kilianska ZM: Personalized therapy tests for the monitoring of chronic lymphocytic leukemia development. Oncol Let 13: 2079-2084, 2017.

16. Montserrat E, Bauman T and Delgado J: Present and future of personalized medicine in CLL. Best Pract Res Clin Haematol 29: 100-110, 2016.

17. Piggin A, Bayly E and Tam CS: Novel agents versus chemotherapy as frontline treatment of CLL. Leuk Lymph 58: 1320-1324, 2017.

18. Rogalińska M and Kiliańska ZM: Potential new agents for chronic lymphocytic leukemia treatment. Anticancer Agents Med Chem 10: 666-682, 2010.

19. Robak T, Stilgenbauer S and Tedeschi A: Front-line treatment of CLL in the era of novel agents. Cancer Treat Rev 53: 70-78, 2017.

20. Hallek M: Role and timing of new drugs in CLL. Hematol Oncol 35 (Suppl 1): S30-S32, 2017.

21. Whittaker S, Mallinger A, Workman P and Clarke PA: Inhibitors of cyclin-dependent kinases as cancer therapeutics. Pharmacol Ther 173: 83-105, 2017.

22. Niesvizky R, Badros AZ, Costa LJ, Ely SA, Singhal SB, Stadtmauer EA, Haideri NA, Yacoub A, Hess G, Lentzsch S, et al: Phase 1/2 study of cyclin-dependent kinase (CDK)4/6 inhibitor palbociclib (PD-0332991) with bortezomib and dexamethasone in relapsed/refractory multiple myeloma. Leuk Lymph 56: 3320-3328, 2015.

23. Edessa D and Sisay M: Recent advances of cyclin-dependent kinases as potential therapeutic targets in HR+/HER2-metastatic breast cancer: A focus on ribociclib. Breast Cancer (Dove Med Press) 9: 567-579, 2017.

24. Blachly JS, Byrd JC and Grever M: Cyclin-dependent kinase inhibitors for the treatment of chronic lymphocytic leukemia. Semin Oncol 43: 265-273, 2016.

25. Chen Y, Germano S, Clements C, Samuel J, Shelmani G, Jayne S, Dryer MJ and Macip S: Pro-survival signal inhibition by CDK inhibitor dinaciclib in Chronic Lymphocytic Leukaemia. Br J Haematol 175: 641-651, 2016.

26. Gucký T, Jorda R,Zatloukal M,Bazgier V,Berka K, ŘezníčkováE, Béres T, Strnad M and Kryštof V: A novel series of highly potent 2,6,9-trisubstituted purine cyclin-dependent kinase inhibitors. J Med Chem 56: 6234-6247, 2013.

27. Haider C, Grubinger M, Rezníčková E, Weiss TS, Rotheneder H, Miklos W, Berger W, Jorda R, Zatloukal M, Gucky T, et al: Novel inhibitors of cyclin-dependent kinases combat hepatocellular carcinoma without inducing chemoresistance. Mol Cancer Ther 12: 1947-1957, 2013.

28. Allegri L, Baldan F, Mio C, Puppin C, Russo D, Kryštof V and Damante G: Effects of BP-14, a novel cyclin-dependent kinase inhibitor, on anaplastic thyroid cancer cells. Oncol Rep 35: 2413-2418, 2016 
29. Rodriguez D, Bretones G, Arango JR, Valdespino V, Campo E, Quesada V and López-Otín C: Molecular pathogenesis of CLL and its evolution. Int J Hematol 101: 219-228, 2015.

30. Tong WG, Chen R, Plunkett W, Siegel D, Sinha R, Harvey RD, Badros AZ, Popplewell L, Coutre S, Fox JA, et al: Phase I and pharmacologic study of SNS-032, a potent and selective Cdk2, 7, and 9 inhibitor, in patients with advanced chronic lymphocytic leukemia and multiple myeloma. J Clin Oncol 28: 3015-3022, 2010.

31. Ge Y, Lei W, Ma Y, Wang Y, Wei B, Chen X, Ru G, He X, Mou X and Wang S: Synergistic antitumor effects of CDK inhibitor SNS-032 and an oncolytic adenovirus co-expressing TRAIL and Smac in pancreatic cancer. Mol Med Rep 15: 3521-3528, 2017.

32. Flynn J, Jones J, Johnson AJ, Andritsos L, Maddocks K, Jaglowski S, Hessler J, Grever MR, Im E, Zhou H, et al: Dinaciclib is a novel cyclin-dependent kinase inhibitor with significant clinical activity in relapsed and refractory chronic lymphocytic leukemia. Leukemia 29: 1524-1529, 2015.

33. Robak P and Robak T: Novel synthetic drugs currently in clinical development for chronic lymphocytic leukemia. Expert Opin Investig Drugs 26: 1249-1265, 2017.

34. Awan FT, Kay NE, Davis ME, Wu W, Geyer SM, Leung N, Jelinek DF, Tschumper RC, Secreto CR, Lin TS, et al: Mcl-1 expression predicts progression-free survival in chronic lymphocytic leukemia patients treated with pentostatin, cyclophosphamide, and rituximab. Blood 113: 535-537, 2009.
35. Kozako T, Suzuki T, Yoshimitsu M, Arima N, Honda S and Soeda S: Anticancer agents targeted to sirtuins. Molecules 19: 20295-20313, 2014.

36. Albayrak A, Halici Z, Cadirci E, Polat B, Karakus E, Bayir Y, Unal D, Atasoy M and Dogrul A: Inflammation and peripheral 5-HT7 receptors: The role of 5-HT7 receptors in carrageenan induced inflammation in rats. Eur J Pharmacol 715: 270-279, 2013.

37. Polat B, Halici Z, Cadirci E, Albayrak A, Karakus E, Bayir Y, Bilen H, Sahin A and Yuksel TN: The effect of alpha-lipoic acid in ovariectomy and inflammation-mediated osteoporosis on the skeletal status of rat bone. Eur J Pharmacol 718: 469-474, 2013.

38. Rogalinska M: The role of mitochondria in cancer induction, progression and changes in metabolism. Mini Rev Med Chem 16: 524-530, 2016.

cc) (7) (5) This work is licensed under a Creative Commons Attribution 4.0 International (CC BY-NC 4.0) License 